\title{
CARTAS ENTRE EDUCADORAS SOCIALES EN AMÉRICA LATINA: COMPRENSIÓN DEL MOMENTO HISTÓRICO VIVIDO
}

\author{
LETTERS BETWEEN SOCIAL EDUCATORS IN LATIN AMERICA: \\ UNDERSTANDING OF THE HISTORICAL MOMENT LIVED
}

\author{
Laura Daniela Ruiz González \\ Cooperativa de Trabajo Homoludens, Uruguay \\ https://orcid.org/0000-0002-1360-3789 \\ lauraruiz.uy@gmail.com \\ Maria Raquel Schettini Castro \\ Instituto Nacional de RehabilitaciónUruguay \\ https://orcid.org/0000-0001-7041-4637 \\ raquelschettini28@gmail.com \\ Jacyara Silva de Paiva \\ Universidad Federal de Espiritú Santo, Brasil \\ https://orcid.org/0000-0002-2917-7673 \\ jacyarapaiva@hotmail.com
}

Recibido: 21-11-2019 Revisado: 11-12-2019 Aceptado: 12-02-2020

Resumen: El objetivo de este artículo es comprender el contexto histórico en América Latina estableciendo una relación con la educación social a través del intercambio de cartas entre tres educadoras sociales, latinoamericanos, que trabajan en el área de educación social en Brasil y Uruguay, mujeres académicas y con un fuerte compromiso político y educativo con las clases populares; este artículo se gesta para incentivar otras reflexiones sobre los procesos de la educación social. En este artículo tendremos la narrativa como una opción metodológica, ya que entendemos que está llena de significados singulares, que permiten la problematización, la comprensión y develan ciertos fenómenos, en este caso, sobre la educación social, los acontecimientos históricos se van tejiendo a partir de partes seleccionadas existencialmente por las narradoras "[...] por lo tanto, la narración no es apenas el producto de un "de contar", ella tiene también un poder de efecto sobre lo que narra" (Delory, 2012, p.82).

Palabras Clave: Contexto histórico, educación social, mujeres, narrativa, política.

\begin{abstract}
The objective of this article is to understand the historical context in Latin America by establishing a relationship with social education through the exchange of letters between three social educators, Latin Americans, who work in the area of social education in Brazil and Uruguay, academic women and with A strong political and educational commitment to the popular classes, this article is designed to encourage other reflections on the processes of social education.In this article we will have the narrative as a methodological option, since we understand that it is full of singular meanings, which allow problematization, understanding and reveal certain phenomena, in this case, on social education, historical events are woven from from parts existentially selected by the narrators "[...] therefore, the narrative is not just the product of um" to tell ", she also has a power of effect on what she narrates" (Delory, 2012, p. 82).
\end{abstract}

Keywords: Historical context, social education, women, narrative, politics.

Cómo citar este artículo: Ruiz, L., Schettini, R., y Silva de Paiva, J. (2020). Cartas entre educadoras sociales en América Latina: comprensión del momento histórico vivido. Hachetetepé. Revista científica en Educación y Comunicación, (20), 86-92. doi: http://doi.org/10.25267/Hachetetepe.2020.i20.10

e-ISSN:2172-7910

Doi: http://doi.org/10.25267/Hachetetepe.2020.i20.10

Universidad de Cádiz 


\section{UN CONTEXTO LLAMADO BRASIL: EL LUGAR DE LA EDUCACIÓN SOCIAL EN ESTE MOMENTO HISTÓRICO}

El mundo sería insoportable sin el sueño de otro mundo.

Desde este punto de vista, la esperanza es precisamente esto, soñar otra situación. La vida humana necesita del sueño para poder vivirse. Joan Carles Melich

Las cartas han sido durante mucho tiempo parte de nuestra historia, la historia de nuestros padres, nuestra gente, aunque la tecnología ha cambiado el formato de las cartas, continúan existiendo, continúan inspirándonos, haciéndonos reflexionar e incluso entender nuestra existencia todos los días. La construcción de narrativas contribuye al proceso de formación e información de quienes piensan sobre la educación social en el mundo y desean comprender un poco más sobre los contextos sociohistóricos de la educación social en América Latina.

No ha sido fácil ser una mujer, una defensora de los derechos humanos, de las políticas públicas sociales, de los oprimidos en Brasil, no es fácil hablar y actuar desde una perspectiva educativa social en un país donde los derechos humanos se quitan todos los días y defender la justicia social se ha convertido en algo "criminal".

En este momento histórico, los movimientos sociales, los activistas políticos parecen retomar su papel con las clases populares y, a pesar de los intensos recortes financieros en las políticas sociales, la Educación Social en Brasil parece estar en camino de empezar a comprender su papel con los oprimidos.

A diferencia de los años 70 y 80 cuando surgió, al final de la dictadura militar cuando se alejó de la academia que no podía entender su práctica pedagógica, hoy la Educación Social en varios estados brasileños, se une a esta academia en un acto de resistencia, resiliencia e incluso de valentía

En Brasil, se han llevado a cabo movimientos de formación permanente a través de la extensión universitaria, en varios estados brasileños, cientos de educadores sociales han estado en las universidades para compartir sus conocimientos, enseñar cómo ocurren las intervenciones pedagógicas en espacios no escolares y también aprender el saber hacer de la Universidad. Ha sido una relación dialógica importante en el contexto de la educación social en Brasil, un campo que se está volviendo muy singular.

El principal campo de acción de los educadores sociales brasileños ha sido en las clases populares, especialmente entre los más pobres y negros, la educación social en Brasil tiene este contexto claramente delimitado, ya que tiene los Derechos Humanos como su marca de identidad, actúa pedagógicamente con los más violentados por la pérdida y negación de los derechos humanos: los pobres y los negros de este país.

Teniendo a Freire como su principal referencia teórica, la Educación Social en Brasil se ha constituido como un proceso de emancipación y conciencia de las clases oprimidas, aunque sabemos que la Educación Social no constituye una educación de clase, a través de ella luchamos por la justicia, la equidad social y democracia.

La Educación Social en Brasil nació como Street Education en la década de 1980, como una alternativa pedagógica para niños y adolescentes que tenían a las calles como su hogar, con el proceso educativo que tuvo lugar en las calles de la ciudad de São Paulo y pronto se extendió a otras ciudades. Con ello, aparece el Movimiento Nacional de Niños y Niñas de la Calle de Brasil, un movimiento para defender los derechos de los niños y adolescentes en Brasil que fue esencial en la elaboración del Código de Niños y 
Adolescentes en Brasil, una doctrina de Protección Integral para todos los niños y adolescentes en Brasil.

En un momento histórico de pérdida de derechos, de profundización de las políticas neoliberales de ultraderecha, que oprimen y eliminan los derechos principalmente de los más pobres, la educación social en Brasil se presenta como re (existencia) con los estratos populares, con parte de la universidad brasileña.

En Brasil, la educación social tiene como objetivo caminar y luchar junto a los oprimidos, los más pobres, los que sufren las desigualdades sociales y la violación de los derechos, violación que deshumaniza al otro, hoy nuestra lucha como investigadoras y educadoras sociales es contra el proyecto neoliberal de deshumanización del ser que según Freire (2002: 31). Solo el poder que surge de la debilidad de los oprimidos será lo suficientemente fuerte como para liberar oprimido y al opresor.

Como hemos experimentado, en los últimos 4 años desde la destitución de la Presidenta Dilma Rousseff, graves violaciones de los derechos humanos, entre ellas el debilitamiento de las políticas sociales públicas que tienen como objetivo garantizar los derechos fundamentales de la persona humana, la Educación Social en Brasil se presenta como una de las posibilidades de resistencia a toda esta arbitrariedad.

\section{URUGUAY: EDUCACIÓN SOCIAL Y UN INMINENTE TIEMPO DE RETROCESOS EN MATERIA DE DERECHOS HUMANOS}

¿Cómo estás querida? Qué tiempo tan oportuno para volver a contactarnos e intercambiar. En nuestro pequeño paisito se vienen tiempos turbulentos, siguiendo el viraje que ha tomado Latinoamérica hacia el liberalismo radical y la ebullición de una derecha dogmática y radical que viene conquistando terreno con la religión, el miedo y el odio, como eslogan y profecía.

Comenzamos hace dos años a dar clase en educación social específicamente, justamente en mi ciudad natal, Rivera. Si bien hace ya más de tres lustros que ambas del interior, residimos en Montevideo, este regreso a los orígenes se dio como ningún otro regreso anterior... pues el lugar, el objetivo y las relaciones a establecerse marcarían profundamente la percepción sobre la ciudad, su cultura, la gente y sobre todo la educación social; dando lugar a la necesidad imperante de que algo se mueva, se transforme, se resignifique.

La docencia implica crear y desplegar la idea de una formación que de cierta manera cuestiona el contenido, las formas y las relaciones de lo aprendido y practicado hasta el momento. Quienes se inscriben en esta formación, se encuentran con una experiencia renovadora, como debiera ser toda experiencia educativa que busca meterse con la otra (Antelo, 2005).

Es ahí que se entabla, en el mejor de los casos, un proceso de trabajo sobre sí de cada estudiante que decide avanzar en la formación (cabe decir también de quien ocupa el rol docente) donde la materia "práctico", así como la práctica misma, resulta ser estructurante y fundante para la formación/construcción del oficio de educar.

Asumiendo esta carta como una invitación a narrar, vinculando la idea de borrador, nos gusta mucho pensar en las marcas de la goma... en eso que se borra y en lo que se vuelve a dibujar/trazar sobre lo plasmado anteriormente. Atrae particularmente la idea de volver a comenzar, aunque no sin marcas anteriores, volver a dar sentido a algo que por alguna razón parece haberse agotado o que ya no alcanzaba. Seduce también la idea de subrayar, remarcar y resaltar otros elementos que aún con el paso del tiempo merecen 
seguir estando hasta que en alguna revisada o pasada en limpio devengan en marcas para nuevas esperanzas que permitan sobrevivir, no claudicar en esto de los "oficios del lazo" como se nombra ya hace algún tiempo en el Río de la Plata.

Según Deleuze (1990) el dispositivo es concebido como una red heterogénea que incluye lo dicho y también lo no-dicho, el establecimiento y el discurso, la Ley como universal y el hacer concreto. El dispositivo mismo es la red que se establece entre estos elementos. Agregando a esta concepción lo expuesto por Larrosa (1995) de que un dispositivo pedagógico será, entonces, cualquier lugar en el que se constituye o se transforma la experiencia de sí, cualquier lugar en el que se aprenden o se modifican las relaciones que el sujeto establece consigo mismo. Reconocer la contingencia y la historicidad de esos mismos dispositivos es adoptar un punto de vista genealógico. Desde esta perspectiva, la pedagogía no puede ser vista ya como un espacio neutro o exento de problemas de desarrollo o de mediación, como un mero espacio de posibilidades para el desarrollo o la mejora del autoconocimiento, la autoestima, la autonomía, la autoconfianza, el autocontrol, la autorregulación, etc., sino que produce formas de experiencia de sí en las que los individuos pueden devenir sujetos de un modo particular (Larrosa 1995, p. 22-23). Es en esa red entre los elementos, en donde se modifica la experiencia de sí, que se desarrolla y cobra sentido la práctica educativa.

Es por ello que para llegar al tiempo actual creemos necesario, realizar un breve resumen histórico de la creación y evolución de dicha formación en Educación Social en nuestro país, para situar los desafíos actuales de la misma. La misma nace como una formación para especializar a aquellas personas que se desempeñaban como cuidadoras en los hogares donde viven los niños y niñas que están siendo tutelados por el Estado. Jorge Camors, quien fuera director de CENFORES (en primera instancia Escuela de Funcionarios en 1989), mediante varias publicaciones realiza un recorrido histórico y político de la creación y evolución de la carrera en Uruguay hasta la fecha. Esta profesión en nuestro país buscó generar un corrimiento del paradigma de cuidados al educativo.

En su artículo "Relaciones entre los conceptos y las políticas: posibilidades, dificultades y desafios" deja de manifiesto la necesidad de la formación de los denominados "cuidadores" que estaban en contacto directo con los niños, niñas y adolescentes del entonces Instituto Nacional del Menor, en ese tiempo y espacio se crea una figura que pueda dar un nuevo giro a la relación y acción educativa, como una nueva versión del cuidado que requieren, que como él mismo describe tuvo mucha resistencia. Más adelante menciona que:

Lo social, configuraba un espacio, nuevo por el reconocimiento de los actores que lo integraban porque el objeto pasaba a ser sujeto, el "sujeto de educación" de Violeta Núñez, el niño, niña y adolescente. El hasta entonces protagonista, se debía reubicar como el agente de la educación, el educador" (...) "operar en lo social "educativamente", con la intencionalidad de promover aprendizajes en los participantes, nuevos conocimientos, habilidades y actitudes, no es fácil en sí mismo pero tampoco es fácil que sea comprendido en contexto. Por eso además, es conveniente y necesario "mostrar" y "demostrar" lo que se propone y lo que logran los participantes; fundamentalmente a través de los logros, se podrán obtener los reconocimientos, aún insuficientes, a esta modalidad de educación y a sus profesionales, los educadores sociales (2009, pp.98-99)

En ese entonces se proponía que la creación de la nueva figura profesional y que su plan de formación tuviera una clara y evidente finalidad de transformación 
institucional, de cambios de las modalidades de atención de niños, niñas y adolescentes, de modificaciones en su atención, de modificaciones en la metodología de trabajo en la institución, en los centros, en la función de la dirección y en el trabajo en equipo.

Resulta comprensible "la lucha" que comienza hace más de treinta años, que pretende generar, fundamentar y validar la construcción de una nueva figura profesional de la educación en el campo social; las primeras batallas estuvieron centradas en construir y darle contenido a esa figura que tenía como mayor desafío "correr el foco de la figura del cuidador" para colocar al sujeto educando en el centro (antes objeto de la intervención), posicionándolo como protagonista. La contextualización que realiza Camors permite entender la importancia de visualizar al educando como protagonista del proceso educativo. Sin embargo esto no debiera limitar la reflexión sobre esta figura, no como centro de la relación educativa, pero sí ante todo como sujeto que ocupa un lugar transitorio, para avanzar en el desarrollo de la disciplina, en la calidad de las prácticas educativas, el campo de trabajo, el pensarse como colectivo y no menos importante la Ética profesional en la Educación Social. En Uruguay la población destinataria de este campo fueron históricamente los niños, niñas y adolescentes debido al ámbito de su gestación, aunque con la evolución de la formación, la creación de inúmeras políticas socio educativas implementadas a partir del 2005 en este país cuando llega el Frente Amplio, fuerza de izquierda, a ser gobierno. Con la creación en ese entonces del Ministerio de Desarrollo Social se desplegaron una gran cantidad de políticas de carácter socio educativo que amplificaron el campo profesional en un gran espectro de campos vinculados con la familia, la salud, las personas privadas de libertad e inclusive la educación formal, o más conocida como escuela pública, en Uruguay.

Luego de la creación de la Escuela de Funcionarios en la órbita de INAME, la institución transita por varios momentos históricos hasta que se separan la formación de Educadores Sociales y el curso de perfeccionamiento de educadores impartida en el mismo predio. Más adelante, pasado el año 2000 la Escuela de Funcionarios pasa a ser denominada CENFORES (Centro de Formación de Educadores Sociales), aún en la órbita de Instituto Nacional de la Niñez y Adolescencia (antes denominado INAME). Luego de la aprobación de la Ley General de Educación en diciembre de 2008, la formación pasa a ser impartida por el Consejo De Formación Docente de la Administración Nacional de Educación Pública (ANEP) y transita por una gran reestructura con la finalidad de ser parte de la Universidad de la Educación; Universidad que aún no ha sido creada por falta de respaldo político para su aprobación.

Con la aprobación de la Ley General de Educación en diciembre de 2008, se genera otro punto de inflexión en la vida de la formación, ya que de acuerdo a lo expresado en el artículo 84 de la Ley de Educación la educación social pasa a ser universitaria:

(Creación). - Créase el Instituto Universitario de Educación (IUDE) en el ámbito del Sistema Nacional de Educación Pública que desarrollará actividades de enseñanza, investigación y extensión. Formará maestros, maestros técnicos, educadores sociales y profesores, y otorgará otras titulaciones que la educación nacional requiera (Ley de Educación $\mathrm{N}^{\mathrm{o}}$ 18.437)

Este hecho promueve grandes oportunidades para la profesión, ya que al transformarse en una licenciatura, no solo permitiría la posibilidad de seguir avanzando a nivel formal de estudios; sino que le da el sustento académico necesario para seguir diversificando las prácticas y el accionar en atención directa como también en el marco de la investigación, en la elaboración de pensamiento teórico propio y en la incidencia en

e-ISSN:2172-7910

Doi: http://doi.org/10.25267/Hachetetepe.2020.i20.10

Universidad de Cádiz 
la generación de políticas en el ámbito educativo y social. Además de generarse por primera vez en Uruguay la descentralización de la formación, implementando por primera vez en nuestro país en 2011 ámbitos de formación de dicha profesión en el interior del país. En el informe final de la Comisión de Implementación del Instituto Universitario de Educación[3], entregado en Abril de 2010 se propone un perfil de egreso del IUDE del cual destacamos:

Equipados de cultura general y científica, de una formación académica de calidad, capaces de formular y desarrollar con fundamentos teóricos y flexibilidad su práctica educativa, gestionando la compleja interacción teoría-práctica.

Predispuestos para estar en diálogo permanente con las distintas personas e instituciones con las que trabaja, y siendo parte de la comunidad educativa, ocupándose de pensar y ensayar estrategias diversas de promoción cultural.

Preparados para trabajar en equipo con otros profesionales, y para generar encuentros e intercambios entre instituciones... Preparados para conocer y analizar la situación institucional, sus potencialidades y obstáculos, estando apto para desempeñarse calificadamente en diversos escenarios del campo de trabajo; y capaz de participar activamente de los procesos de debate, construcción y gestión de las políticas educativas (Comisión de Implementación, 2010, p.17)

Como planteábamos anteriormente, si bien aún no se ha conseguido el respaldo en el parlamento para la creación de la Universidad de la Educación, institucionalidad que devendría luego del IUDE, las transformación en la formación y en el campo profesional son impresionantes desde la evolución del paradigma tutelar al paradigma de los Derechos Humanos. Sin embargo, con la victoria de un gobierno de coalición de derecha luego de 15 años de gobiernos de izquierda pone en alerta a la educación social, así como toda la comunidad educativa, por la regresión en la conquista de derechos y la inminente criminalización de la pobreza.

A pocas semanas de la Asunción de la derecha se presenta una Ley de Urgente Consideración (que será aprobada en breve debido a la legislación vigente.) donde propone recortar derechos, privatizaciones, flexibilización del mercado, disolución de los consejos de salarios, quita de autonomía a los gremios y los consejos docentes, reducción de la potestad de la Universidad, así como brinda contundentes privilegios a grupos de poder como los medios de comunicación, grandes empresarios en general y a grandes productores rurales en particular. En tiempos donde la re-distribución social y las políticas que apuntan a la igualdad habrá que juntarse, habrá que resistir... y sobre todo habrá que educar, ya no para el mercado y el consumo, sino para ensayar una sociedad más justa, empática, comunitaria y con memoria... he aquí el gran desafío de la educación social y de la educación en general.

\section{EN LAS CARTAS, POR EL ENCUENTRO, CON CONVICCIÓN Y ESPERANZA, EN LA LUCHA SIEMPRE}

El diálogo a través de las cartas nos permite escuchar la voz del otro, percibiendo el contexto social, cultural, económico y político en el cual nosotras mujeres, educadoras, investigadoras en educación social estamos inmersas, y mientras hablamos de educación social, dejamos entrever cómo todos estos factores influyen en nuestra constitución como persona y como profesional. 
Las narraciones presentadas aquí desvelan nuestra historicidad entrelazada con la educación social de nuestros países, y nos hacen regresar a nosotras mismas y a nuestros contextos en un rápido proceso de reflexión.

Nos damos cuenta de cuán únicas y similares son las historias de nuestros países, nuestra lucha por la educación social, nuestra lucha por los derechos humanos y por un mundo donde la justicia social sea para todas y todos. La educación social, tanto en Brasil como en Uruguay, se presenta como una especie de "inédito viable" (Freire, 2002), una categoría Freiriana que nos habla de creencias, sueños, valores, límites, ansiedades y, sobre todo, posibilidades, porque el inédito viable habla de sueños colectivos, de la transformación de las personas y del mundo.

Intentamos a través de esta narrativa compartir nuestras historias como mujeres latinoamericanas, investigadoras y educadoras sociales, en la construcción de proyectos colectivos, por la realización de la utopía de la humanización, de la democracia auténtica, en un mundo donde todas y todos puedan encajar y tengan sus derechos asegurados. ¡Seguimos luchando colectivamente!

\section{REFERENCIAS BIBLIOGRÁFICAS}

Antelo, E.(2005). Notas sobre la (incalculable) experiencia de educar" en "Educar: ese acto político. Compilado por Frigerio, G y Diker, G. Buenos Aires: Del Estante Editorial.

Camors, J. (2012). El Educador Social en Uruguay. Aspectos históricos y fundamentos que explican la construcción de la figura profesional. Montevideo, Uruguay: Edit. Grupo Magro.

Camors, J.(2009). Educación social acto político y ejercicio profesional. ADESU MEC Montevideo Uruguay.

Comisión de Implementación del IUDE. (2010). Informe final comisión de implantación del IUDE. Disponible en: https://educacion.mec.gub.uy/informe final comision de implantación del IUDE.pdf

Deleuze, G. (1990) ¿Qué es un dispositivo? En E. Balbier, G. Deleuze, G. y L. Hubert (eds.) Michel Foucault filósofo. Barcelona: Gedisa.

Delory, M. (2012). Pesquisa biográfica: projeto epistemológico e perspectivas metodológicas. Em M. Abrahão y M Passeggi. M. (Orgs.). Dimensões epistemológicas e metodológicas da pesquisa (auto) biográfica (pp. 71-93) Tomo I. Natal: EDUFRN: Porto Alegre: EDIPUCRS - Salvador: EDUNEB.

Freire, P. (2002) Pedagogia do Oprimido. Rio de Janeiro: Ed. Paz e Terra.

Larrosa, J.(1995). Tecnologías del yo y educación (Notas sobre la construcción y la mediación pedagógica de la experiencia de sí). En J. Larrosa, Escuela, poder y subjetivación. Madrid: La Piqueta. 